\title{
From Expository Teaching to First e-Learning Course Production: Capture in a 17 Online Course Sample of a Pedagogical Pattern Facilitating Transition
}

\author{
Dominique Verpoorten, Marianne Poumay, Séverine Delcomminette, Dieudonné Leclercq \\ Research Officer Director (LabSET-ULg) Researcher Academic Supervisor \\ dominique.verpoorten@ulg.ac.be, $\underline{\text { m.poumav@ulg.ac.be, severine.delcomminette@ulg.ac.be, d.leclercq@ulg.ac.be }}$
}

\begin{abstract}
This paper discusses an activity structure, RQAT, mined from a study of 17 on-line courses. It formats this structure as a pedagogical pattern and presents it as an abstraction to support staff development, especially faculty willing to incorporate first online components to enhance face to face course.
\end{abstract}

\section{Introduction}

"A pattern is a named nugget of insight that conveys the essence of a proven solution to a recurring problem within a certain context amidst competing concerns" [1]. Based on an "inductive" [2] and "opportunistic" [3] methodology, LabSET (Support Laboratory for Telematic Learning) inspected 17 online courses developed at the University of Liège (Belgium). The process unearthed 11 instances of an activity structure named RQAT. The structure is composed of three learning events. In the first one, the student receives material to read $(\mathrm{R})$. In the second, he asks questions to the teacher $(\mathrm{Q} \& A)$. In the third one, he performs a test $(\mathrm{T})$ on the content read and clarified. For some professional educators, this pattern may, at first sight, seem obvious. However, for many teachers who authored an online course according to RQAT, the pattern represents a sweeping change, leading them (and their students) from a "chalk and talk" course to blended or full e-learning, from pure "transmission/reception" to a more task-based and student-centered method. Therefore, it might be not trivial to document a pattern which enabled a good deal of trainers to cross those lines. In the first section, we express the RQAT recurring learning design in an Alexandrian pattern format. In the second section, we elaborate on prospects for using pedagogical patterns as conceptual support tools for teacher professional development.

\section{RQAT expressed in a pattern format}

Patterns can be seen as solutions bridging between empirical evidence, experience, theory and the practical problems of design. "Patterns are not created or invented; they are identified via an invariant principle (of good design) as manifest across different places and cultures" [4]. The recurrence of RQAT legitimized an attempt to express it in a pedagogical pattern format suggested by [5] and sticking to the fundamental principles of Alexandrian patterns [6].

\subsection{Name}

RQAT (Reading-Questions/Answers-Test)

\subsection{A Picture (Showing an archetypal example of the pattern)}

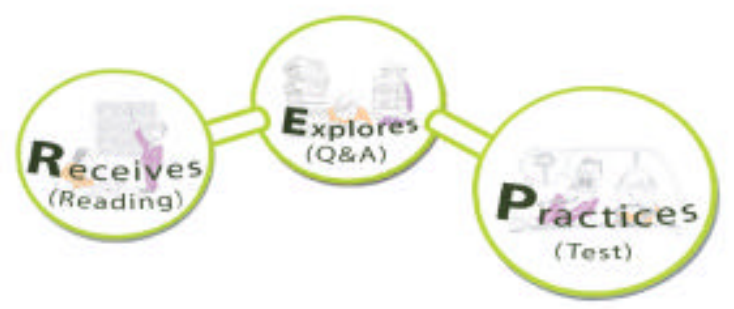

(The pedagogical patterns movement originates in architecture. In this domain, it seems obvious to provide the illustration of a pattern. When it comes to pedagogy, it becomes a challenge. More generally, "user-friendly" visualization of pedagogical scenarios or patterns is an issue discussed today $[1,7,8]$. The one proposed is inspired from the "8 Learning events 
model" [9] which provides illustrations for 8 basic teaching and learning activities ).

\subsection{Context (how the pattern helps to complete some larger patterns)}

The RQAT pattern is mainly concerned with the establishment of appropriate organizational forms for promoting personal and active appropriation of content. It presents as an alternative to traditional lectures delivered to large groups of students. The pattern has wide applicability to almost every domain, for literary topics or for mathematics and sciences. It can be used in face-to-face settings but can be implemented, like in the sample, in an e-learning mode.

\subsection{Problem Headline (to give the essence of the problem in one or two sentences)}

Traditional lecture delivery of course content in large groups quite often ends up in a good deal students "switching off". How can instructors facilitate the rise of all learners' level of mental activity in the content appropriation process?

2.5. Body of the Problem (its empirical background, evidence for its validity, its analysis, its rationale, examples of different ways by which the pattern can be manifested)

Teachers giving lectures to large audience experiment frequently students' passivity. According to [10], an active participation implies that the learner has mastered the prerequisites. Attending a course without being "impregnated" to some degree with the content reduces the expected benefit of this participation. Conversely, individual preparation provides the student with a first representation of the topic, allows the "subsumption" process [11] to occur, and supports more commitment and (mental or observable) participation. The removal of the conventional lecture and its substitution with a Q\&A session, as suggested by RQAT, is an additional step towards passivity reduction. The course period is used for answering learners' questions on the content read, discussing and criticizing it. Such an approach of the content, left at the students' initiative, is still kept very limited in the traditional "learning-by-being-taught" whilst they produce a more in-depth learning [10]. Additionally, reading material before the lesson and preparing oneself to ask questions about it during the course benefits the student as it trains him/her to be more autonomous and responsible, especially when a formative test closes the sequence and gives him/her an indication about the knowledge level he/she achieved. RQAT is drawn from genuine teaching practice since it emerged as a pattern from the observation of existing courses. Nevertheless, the "problem-solution" couple it instantiates received a first theorization by $[10,12]$.

\subsection{Solution (Stated as an instruction, so that you know what to do to build the pattern)}

Use the RQAT structure, or one of its variants, as a substitute for traditional lecture delivery of course content. For that, make sure: to get students engaged with material before the course time, to consider the course more as series of workshops than of lectures, to warn students that a test will be the closing activity of the sequence and have this test ready.

\subsection{A Diagrammatic Representation of the Solution}

We see this section as redundant with the section 2.1.

\subsection{Embellishment (to link the pattern to smaller patterns needed to complete it)}

An assignment to read the material before the course does not mean that the material will actually be read by all students. It would be logical to link RQAT to existing or forthcoming patterns addressing this issue and outlining solutions. It should be possible and useful also to link the Q\&A activity to smaller patterns related to knowledge-sharing, questioning and critique through discussion, for example, the pattern "Learning through discussion" [13] or the pattern "Honor questions" [14].

\section{Patterns as Staff Development Tool}

Discussions of the importance of RQAT in an online environment can go two ways. Firstly, interviews with course owners make it appear that the RQAT pedagogical pattern is of interest to educators (and learners) since they see it as an effective design solution for tackling the following general problems in pedagogy: high quantity of lecturing, low level of individual participation in large groups settings, lack of preparation by students for class time, lack of time for discussion in class. But RQAT can also be of interest 
to those in charge of promoting e-learning among academy because this pedagogical pattern presents as a solution spontaneously and regularly fostered by practitioners willing to make a first step towards the integration of technologies into their teaching practice. From a faculty development viewpoint, RQAT is easily adopted, adapted and implemented by teachers. Not revolutionary, but realistic and flexible, RQAT stands as a good guidance and bridge for going from a conventional expository teaching method to an approach more concerned by learning. As a competing concern to RQAT, it can be mentioned that the pattern remains content-oriented. Yet, for teachers committed to this orientation, the pattern represents both a reassuring ground and an exploratory territory. This intermediate position might explain partly why teachers willing to make a first move towards e-learning embrace this pattern rather naturally. Lastly and more generally, the use of pedagogical patterns as teacher professional development tools is an issue worth being investigated. It is a big step for teachers to start thinking about their courses instead of "just making a course". Consequently, tools and guidance helping to trigger self-reflection about one's own practice are needed. "But practitioners, quite reasonably, complain if the guidance they are given appears too vague or is unsupported by research. Equally, they resist tight prescription - whether it be prescription of the technology to be used, or the pedagogical strategies to be employed" [5]. As organizational and communicative open frameworks, we think that pedagogical patterns, such as RQAT, locate at this right level between rigour and prescription. They offer principled, structured but flexible resource. They suggest rather than prescribe a solution. They offer guidance but require adaptation and embellishment. They embed promise of reuse in that they provide users with the freedom to contextualize them, meaning that the reuse occurs only through an active appropriation by the teacher [14]. For those reasons, we believe that pedagogical patterns can be worth using as staff development vehicles when considered as the basis for discussion and collaborative work with teachers, allowing them to identify, clarify the components of their own practice and stimulate their educational openness and creativity.

\section{Acknowledgement}

This work would not have been possible without the funding provided by the European project iClass.
[1] Appleton, B., (2000). Patterns and Software: Essential Concepts and Terminology. Available: http://www.enteract.com/ bradapp/docs/patterns-intro.html [2] Brouns, F., Koper, R., Manderveld, J., van Bruggen, J., Sloep, P., van Rosmalen, P., Tattersall, C., \& Vogten, H. (2005). A first exploration of an inductive analysis approach for detecting learning design patterns. Journal of Interactive Media in Education (Advances in Learning Design. Special Issue, eds. Colin Tattersall, Rob Koper), 2005/03. ISSN:1365-893X Available: http://dspace.ou.nl/bitstream/1820/437/1/learning-design patterns-jime.pdf

[3] E-LEN. (2004). Design patterns and how to produce them. Available: http://www2.tisip.no/ELEN/documents/ELEN-Deliverables/booklet-e-

len_design_experience.pdf

[4] Fincher, S. \& Utting, I. (2002). Pedagogical patterns: their place in the genre. In Proceedings of the 7th annual conference on Innovation and technology in computer science education, June. Available: http://www.cs.kent.ac.uk/people/staff/saf/patterns/iticse2002 .pdf

[5] Goodyear, P., Avgeriou, P., Baggetun, R., Bartoluzzi, S., Retalis, S., Ronteltap, F., \& Rusman, E. (2004). "Towards a pattern language for networked learning", Proceedings of Networked Learning 2004.

[6] Alexander, C., Ishikawa, S., Silverstein, M., Jacobson, M., Fiksdahl-King, I., \& Angel, S. (1977). A pattern language: towns, buildings, construction. New York: Oxford University Press.

[7] Griffiths, D. \& Blat, J. (2005). "The Role Of Teachers In Editing And Authoring Units Of Learning Using Ims Learning Design", International Journal on Advanced Technology for Learning (ATL),ISSN 1710- 2251,Special issue on Designing Learning Activities:From Content-based to Context-based Learning Services,vol.2(3),October.

[8] Richards G., Knight C. (2005). Learning Design and Representations of Instructional content, discussion paper for Unfold project. Available: https://www.unfoldproject.net/UNFOLD/about_folder/events/online/griff [9] Leclercq, D. \& Poumay, M. (2005). The 8 learning Events Model. Release 2005.1. LabSET, University of Liège. Available: http://www.labset.net/media/prod/8LEM.pdf

[10] Leclercq, D., Denis, B., Jans, V., Poumay, M., \& Gilles J-L. (1998). L'amphithéâtre électronique, une application : le LQRT-SAFE. In D. Leclercq. Pour une pédagogie universitaire de qualité. Sprimont, Belgique : Mardaga.

[11] Ausubel, D., Novak, J., \& Hanesian, H. (1978). Educational Psychology: A Cognitive View (2nd Ed.). New York: Holt, Rinehart \& Winston.

\section{References}


[12] Gibbs, G. \& Jenkins, A. (1992). Teaching large classes in higher education. How to maintain quality with reduced resources. London : Kogan Page.

[13] McAndrew, P, Goodyear, P \& Dalziel, J. (2004). Patterns, designs and activities: unifying descriptions of learning structures. Open University. Available: http://kn.open.ac.uk/public/document.cfm?docid=5295
[14] Fricke, A. \& Voelter, M. (2003), Honor questions. In Bergin, J, Eckstein, J., Manns, M.L. \& Sharp, H, editors, Patterns for active learning. The Pedagogical Patterns project. Available: http://www.pedagogicalpatterns.org

[15] UNFOLD (2004). Transcript of the Barcelona CoP meeting. Available: https://www.unfoldproject.net/UNFOLD/about_folder/events/cops/f2fbarcelona/ transcript 